\title{
NUEVAS FORMAS DE COMERCIO Y CONSUMO EN MADRID: LAS GRANDES SUPERFICIES
}

\author{
POR \\ EULALIA RUIZ PALOMEQUE \\ ENRIQUE POZO RIVERA \\ M. ${ }^{a}$ LUISA DE LÁZARO Y TORRES
}

\section{Introducción}

En las grandes ciudades españolas la transformación de las estructuras comerciales es relativamente reciente.

En primer lugar se han ido produciendo cambios en el consumo por la acción de numerosos factores entre los que destacan los siguientes. La incorporación de la mujer al trabajo y el mayor número de hogares unipersonales y de parejas sin hijos provoca una menor disponibilidad de tiempo para la realización de las compras, que pasan a tener un carácter semanal o quincenal. La dispersión temporal de las compras se acentúa por la generalización del frigorífico y otros electrodomésticos en los hogares. El incremento del nivel de renta de la población ha posibilitado una mayor capacidad de compra, una diversificación del gasto, y el deseo de los consumidores de realizar sus compras en aquellos locales que por su surtido completo permitan comparar calidad y precios; así mismo incide en la aparición de submercados específicos dedicados a la población infantil, juvenil o de la tercera edad entre otros. El aumento en los niveles de motorización amplía la movilidad del consumidor y le permite la

Eulalia Ruiz Palomeque, Enrique Pozo Rivera, M. ${ }^{a}$ Luisa de Lázaro y Torres: Departamento de Geografía Humana, Universidad Complutense. Madrid.

Estudios Geográficos

Tomo LXI, 2000, n. ${ }^{\circ} 238$, enero-marzo 
realización de compras más voluminosas. La mayor información del consumidor vinculada al fuerte desarrollo de la publicidad modifica los sistemas de venta al disminuir la importancia del vendedor, auténtico intermediario comercial entre el consumidor y el producto. Todos estos factores, entre otros, han posibilitado la aparición de nuevos tipos de consumidores y de nuevos hábitos de compra.

En segundo lugar se está produciendo una reestructuración empresarial, con un incremento de la gestión más profesionalizada y moderna, por parte de distintas sociedades anónimas, y una disminución de la tradicional y aún mayoritaria pequeña empresa familiar. A esto se añade una creciente concentración e internacionalización del capital empresarial. Los establecimientos basados en formas de venta modernas como el libre servicio son cada vez más numerosos, pero su propiedad se encuentra en manos de unas pocas cadenas de distribución, con una gran presencia del capital extranjero desde la apertura del país al exterior.

En tercer lugar se produce un cambio en el tipo de establecimiento. Las nuevas formas de consumo y ocio, las exigencias de los consumidores y los nuevos sistemas de venta, favorecen el incremento del tamaño de los establecimientos comerciales.

La forma más visible de todos estos cambios la constituye la proliferación de las grandes superficies comerciales. Hipermercados y centros comerciales son un claro ejemplo, por sus dimensiones, del incremento en el tamaño de los establecimientos. Lo son también de la concentración del capital como demuestra el que tan solo seis cadenas de distribución, de las que cuatro son extranjeras, posean algo más del 35\% de las grandes superficies y cerca del $50 \%$ de toda la superficie de venta en esta forma de comercio. Y lo son, de una mejor adaptación a las nuevas formas de consumo como se demuestra por el espectacular incremento en su cuota de mercado en detrimento del pequeño comercio.

La creciente presencia de las grandes superficies está teniendo en el conjunto metropolitano madrileño dos consecuencias importantes. Por un lado ha modificado la estructura comercial en dos sentidos. Primero sustituyendo la tradicional homogeneidad comercial, basada en el dominio de la pequeña empresa familiar, por una mayor heterogeneidad en la que el pequeño comercio compite con las grandes superficies. Así en 1995 éstas engloban ya el 25\% y el 34\% de toda la superficie comercial en Madrid y la corona metropolitana. Segundo forzando a los pequeños comerciantes a desarrollar toda una serie de estrategias (especialización, in- 
tegración comercial, formación de cooperativas, desarrollo de franquicias...) encaminadas a aumentar su competitividad. Por otro lado se ha modificado la organización espacial del comercio. Se ha pasado de una situación caracterizada por la oposición entre un centro de Madrid que concentra la mayor parte de los comercios y la superficie de venta, y una periferia y núcleos suburbanos infradotados, a la actual, más equilibrada, con una corona metropolitana que supera en nivel de dotación/habitante a la Capital. La proliferación, a veces excesiva, de las grandes superficies ha reducido el déficit comercial de los núcleos metropolitanos aumentando su peso comercial, hasta el punto de concentrar hoy el $40 \%$ de la superficie comercial de la CAM.

El planeamiento ha abordado estos cambios a lo largo del tiempo mediante las distintas figuras referidas a la actividad comercial que pasamos a desarrollar.

\section{Planificación y comercio en Madrid}

La concepción del planeamiento de los últimos años permite distinguir dos etapas, una hasta mediados de los años ochenta y otra hasta la actualidad. En la primera etapa COPLACO establece un planeamiento de rango superior (1963) a escala de área metropolitana con unas directrices a desarrollar por los diferentes planes de ordenación urbana de los municipios integrados en ella. La mayoría de ellos, redactados a finales de los sesenta y primera mitad de los setenta, son simples planes de extensión del casco urbano. En algunos se reserva suelo para equipamientos sin especificar usos concretos, pero en otros ya se hacen reservas importantes de suelo comercial (Alcobendas, Getafe, Leganés...). En la segunda etapa y tras las transferencias de las competencias en Ordenación del Territorio y Urbanismo a la Comunidad Autónoma de Madrid en 1984 con la consiguiente desaparición de COPLACO, la filosofía del planeamiento cambia. No se elabora un nuevo Plan General del Area Metropolitana de Madrid, sino que cada municipio establece su propio Plan General. Se propone recuperar el espacio urbano y terminar la ciudad solventando el problema de los déficits de dotaciones. En la actividad comercial se plantea la creación de los centros integrados en suelo urbano consolidado. De esta forma se reestructurarían y reequilibrarían los núcleos existentes. En suelo urbanizable se promueven grandes 
áreas para uso terciario bajo distintas tipologías: parques comerciales, parques empresariales, áreas de centralidad... en las que se incluye el uso comercial, a desarrollar por distintos planes parciales (PP) y planes de actuación urbanística (PAU). Este planteamiento teórico sólo se ha recogido en algunos planes generales (Madrid, Fuenlabrada, Coslada...). Sin embargo lo que se ha realizado ha sido distinto. La mayoría de los centros integrados no existen y en algún caso sobre ese suelo se han localizado grandes hipermercados (Villaverde). En cambio lo propuesto en suelo urbanizable se ha realizado.

a) Desarrollo del planeamiento anterior a los años ochenta: El planeamiento anterior a 1985 tiene la finalidad de descongestionar las áreas centrales desplazando la localización de establecimientos estrictamente comerciales hacia la periferia madrileña y núcleos del área metropolitana.

El Plan General de Ordenación Urbana del Área Metropolitana de Madrid (1963) surge a partir de la Ley sobre Régimen del suelo y Ordenación Urbana de 1956, por el que el planeamiento municipal y comarcal se desarrollará en planes generales y parciales de ordenación urbana. En el Plan anterior de Ordenación Urbana de Madrid y sus alrededores (1946) la zonificación comercial se planteó para descongestionar el centro con una distribución de nuevos centros comerciales de barrio, de distrito y de capitalidad. Entre los centros comerciales de distrito tenemos el antecedente de la actual Vaguada (cuadro I: B. del Pilar). A las zonas comerciales en el Plan del 63 se añaden las de nuevas localizaciones de usos comerciales. Entre ellas destacan en el núcleo central las de Avenida del Generalísimo (hoy paseo de la Castellana) y la zona de remodelación de la estación de Atocha. En los distritos periféricos se reservan zonas comerciales necesarias en el centro de gravedad del área del suelo urbano al que prestarán servicio, concibiéndolos en manzana abierta con espacios libres, exentos de circulación rodada.

El Plan Especial del Gran Equipamiento Comercial Metropolitano de Madrid (1974) se justifica por la necesidad de ordenación y previsión de reserva de suelo ante un desarrollo urbano incontrolado y por el creciente interés del sector privado en el establecimiento de unidades comerciales $\mathrm{y}$ de servicios de grandes dimensiones. A partir de este momento se formula por primera vez la ordenación de los centros de equipamiento comercial metropolitanos. 
Entre las directrices principales del Plan podemos destacar la localización de los grandes equipamientos comerciales teniendo en cuenta la accesibilidad por transporte público, y su conexión con los cinturones de circunvalación más alejados del mismo con el fin de no perjudicar la actividad de los centros ya existentes. Además se toma en consideración la previsible evolución de las formas comerciales.

Con todo esto se pretende: a) resolver el déficit de equipamiento comercial existente a corto plazo tanto cuantitativa como cualitativamente; b) establecer una política comercial que a la vez que resuelve los problemas y déficit actuales sirva de conexión con la política comercial a largo plazo que se formule en el futuro Plan Director a elaborar por COPLACO; c) considerar los equipamientos comerciales como parte integrante del sistema urbano, en relación con el resto de las actividades urbanas, y por consiguiente formular la política de asentamiento comercial en relación a su capacidad estructurante, por su poder de atracción de otras actividades; d) establecer unas propuestas de localización del gran equipamiento comercial en relación con el sistema de transporte público y la accesibilidad peatonal; e) proponer unos centros metropolitanos comerciales que incluyan desde el pequeño comercio hasta las nuevas formas comerciales.

Este Plan propone dos tipos de equipamiento comercial: Centros Metropolitanos y Centros de Equipamiento Comercial Exterior. Ambas tipologías se han de localizar en espacios contiguos a vías arteriales radiales, además de ferrocarril y metropolitano, para captar la demanda de las áreas exteriores.

Se propone la localización de los cinco Centros Metropolitanos en espacios del propio término municipal que estén próximos a áreas deficitarias densamente pobladas y con baja accesibilidad, que a la vez permitan descongestionar las áreas centrales, y liberarlas de funciones no específicamente centrales, así como en la proximidad de los asentamientos existentes de población con accesibilidad peatonal. Mientras los cuatro Centros de Equipamiento Comercial Exterior se localizan en los municipios del área metropolitana de Madrid, donde no ejerzan competencia excesiva con centros urbanos incipientes o con núcleos urbanos importantes que permitan la localización de grandes centros comerciales a largo plazo, a distancia que permita un efecto descentralizador que limite la congestión de las áreas centrales y capte la demanda de núcleos exteriores infradotados (cuadros I y II). 


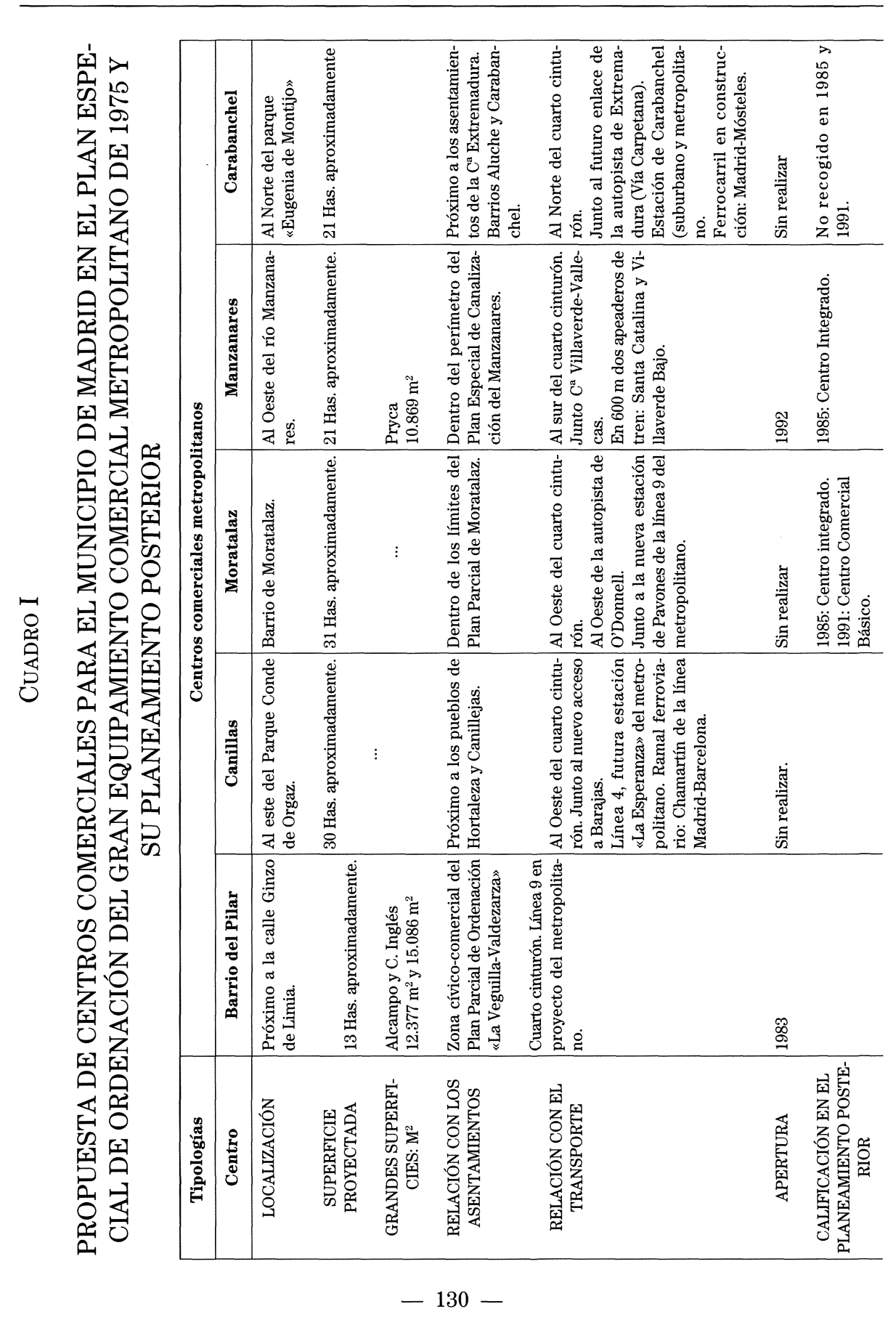




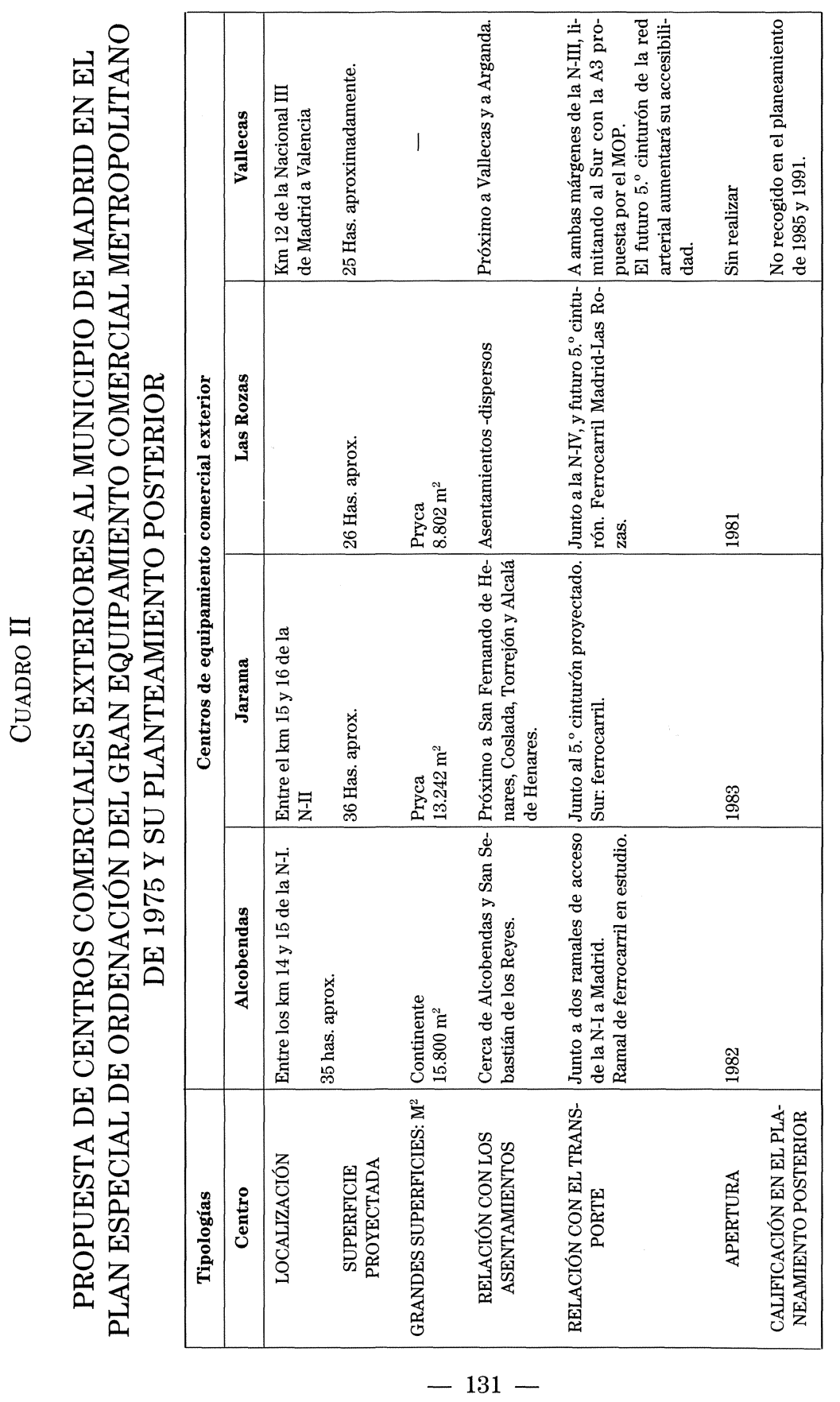


b) Desarrollo del planeamiento a partir de los años ochenta: El planeamiento queda en manos de los municipios, sin un marco general intermunicipal. Los distintos planes generales municipales del Área Metropolitana afrontan los déficits comerciales con actuaciones integradas donde se imbrica lo comercial con la dotación de equipamientos y actividades de ocio.

En la capital, El Plan General de Ordenación Urbana (1985), propone un modelo de ciudad que pretende una recuperación del espacio urbano con el propósito de terminar la ciudad, reconduciendo los procesos de transformación y de colmatación de la ciudad inacabada. Los objetivos son los siguientes: a) rechazo del funcionamiento espontáneo del mercado del suelo y construcción de establecimientos comerciales regulándolos administrativamente; b) creación de espacios comunitarios de valor funcional y simbólico conformados en torno a los edificios y dotaciones que prestan servicios colectivos; c) establecer una adecuada política del terciario comercial en áreas infradotadas, para lo que plantean las calificaciones comerciales de los APD (Áreas de Planeamiento Diferenciado, que en realidad son proyectos heredados de Planes anteriores); d) se propone crear seis Centros de Comercio Básico (tres en el Ensanche Este, al Este y Sur de San Blas; Latina, hoy colonia del Lucero; Carabanchel en la avenida de los Poblados; y Canillejas en San Blas) de iniciativa municipal, que adecúa a las nuevas necesidades el mercado de abastos tradicional, y dieciocho Centros Integrados, concebidos como centros que aúnan los servicios comerciales y los equipamientos, en los que el ayuntamiento coordina todas las actuaciones de las administraciones públicas participantes (cuadro III).

El Plan General de Ordenación Urbana (1997), defiende un cambio de modelo territorial, al pasar de un intento de consolidación de la ciudad en el plan anterior a un modelo metropolitano «que asuma sus funciones de máxima centralidad y difusora de innovaciones y desarrollo hacia otros lugares de su región metropolitana», concibiendo Madrid como un «gran centro de consumo» dentro del sistema de ciudades españolas y de la Unión Europea. Los objetivos propuestos son: a) cubrir los déficit comerciales y de equipamientos detectados en las áreas periféricas; b) apoyar la descongestión del área central frenando su proceso de terciarización; c) creación de centros comerciales, con capacidad estructurante que limiten los desplazamientos masivos al centro. 
CUADRO III:

CENTROS COMERCIALES PROPUESTOS EN EL PLAN GENERAL DE ORDENACIÓN URBANA DE 1985

\begin{tabular}{|c|c|c|c|c|}
\hline \multicolumn{5}{|c|}{ Centros integrados PGOU-85 } \\
\hline \multicolumn{4}{|c|}{$1 .^{\circ}$ cuatrienio $(1985-89)$} & \multirow[t]{2}{*}{$\begin{array}{c}2^{\mathrm{a}} \text { cuatrienio } \\
(1989-92)\end{array}$} \\
\hline Nombre & $\begin{array}{l}\text { Superficie } \\
\text { proyectada }\end{array}$ & Fecha & Tipología & \\
\hline Saconia (Valdezarza) & $\left.14.168 \mathrm{~m}^{2} / 2.000 \mathrm{~m}^{2}{ }^{*}\right)$ & 1991 & Pequeño comercio & Fuencarral \\
\hline Oroquieta & $37.770 \mathrm{~m}^{2 / 10.869 \mathrm{~m}} 2\left(^{*}\right)$ & 1992 & Pryca & Hortaleza (pueblo) \\
\hline Vicálvaro & $9.400 \mathrm{~m}^{2} / 2.500\left(^{*}\right)$ & 1991 & Pequeño comercio & Barajas aeropuerto \\
\hline Aluche & $\left.21.000 \mathrm{~m}^{2} / 11.000 \mathrm{~m}^{2}{ }^{*}\right)$ & 1991 & Continente & Moratalaz \\
\hline Caño Roto & $7.700 \mathrm{~m}^{2}$ & & & Moratalaz Este \\
\hline Manoteras & $5.600 \mathrm{~m}^{2}$ & & & Peña Grande \\
\hline Barajas pueblo & $9.218 \mathrm{~m}^{2}$ & & & \\
\hline Orcasitas & $9.690 \mathrm{~m}^{2}$ & & & \\
\hline San Fermín & $7.000 \mathrm{~m}^{2}$ & & & \\
\hline Vallecas/Palomeras & $7.653 \mathrm{~m}^{2}$ & & & \\
\hline Salamanca & & & & \\
\hline San Blas & \multicolumn{4}{|c|}{ Replanteado en operación comercial más amplia: Eje calle Alcalá. } \\
\hline
\end{tabular}

Nota: Los centros integrados del segundo cuatrienio, en el Avance de 1993 aparecen como centros comerciales básicos.

Todo ello se regulará por el «Plan Especial Terciario de Grandes Superficies Comerciales», que se programa redactar en los dos primeros años de vigencia del Plan General.

En tanto sea aprobado el Plan Especial Terciario se autorizan Grandes Superficies Comerciales en áreas de Planeamiento Incorporado en las que el planeamiento asumido hubiera autorizado ya expresamente la existencia de aquellas, así como en áreas de Suelo Urbanizable Incorporado en las que se hayan previsto. La Licencia de Apertura de Grandes Establecimientos Comerciales (LAGEC) la concede la Comunidad Autónoma de Madrid y es requisito imprescindible para obtener la licencia comercial municipal. Todo esto se regula por la Orden 3323/1996, de 16 de abril, de la Consejería de Economía y Empleo.

En los Planes Generales de los municipios de espacio metropolitano de Madrid las grandes superficies comerciales tienen dos pautas de localización. La primera en el suelo urbano consolidado aprovechando reservas de suelo existentes para equipamientos aún no ocupadas o vin- 
culadas a operaciones de renovación urbana. La segunda, periférica, en suelo urbanizable en lugares de máxima accesibilidad en relación con las grandes vías de comunicación y en las áreas contempladas en los respectivos planes generales como terciarias. En algunos planes generales, como por ejemplo, en Móstoles y Rivas-Vaciamadrid a estas actuaciones se les da una vocación comarcal-metropolitana.

Las grandes superficies comerciales en el espacio metropolitano madrileño

Las distintas figuras de planeamiento señaladas anteriormente han intentado responder a las transformaciones acaecidas en el sector comercial en los últimos veinte años. Los organismos oficiales consideran como grandes superficies a los establecimientos o agrupaciones de establecimientos con una gerencia e imagen unitarias y una superficie de ventas superior a $\operatorname{los} 2500 \mathrm{~m}^{2}$. Los establecimientos aislados se clasifican en grandes almacenes, almacenes populares e hipermercados, mientras que los centros comerciales constituyen un conjunto de establecimientos independientes planificados y desarrollados por una o varias entidades. Esta última forma de comercio es la dominante en el conjunto metropolitano y puede albergar dentro de sí a cualquiera de las otras tipificadas. De hecho la mayoría de los hipermercados madrileños se integran en centros comerciales. Por ello se ha diferenciado dos subtipos de centros comerciales en función de si integran o no a un hipermercado . A estas formas comerciales habría que añadir las grandes superficies especializadas, con una oferta comercial amplia dentro de una sola gama de productos.

El análisis temporal de las grandes superficies (figuras 1 y 2) muestra una clara diferencia entre los almacenes con sus dos tipos, los centros comerciales y los grandes centros especializados. En Madrid los primeros almacenes surgen antes de la Guerra Civil, pero va a ser en los años cuarenta cuando se produzca su despegue definitivo con la aparición de las dos grandes empresas (El Corte Inglés y Galerías Preciados) que han controlado este mercado hasta la actualidad. Esta forma de comercio es la dominante hasta mediados de los años setenta, con un período de fuerte expansión entre 1965 y 1974, coincidiendo con los años de mayor expansión económica del País. A partir de ese año los almacenes abiertos son escasos y en muchos casos se integran en centros comerciales más amplios. 


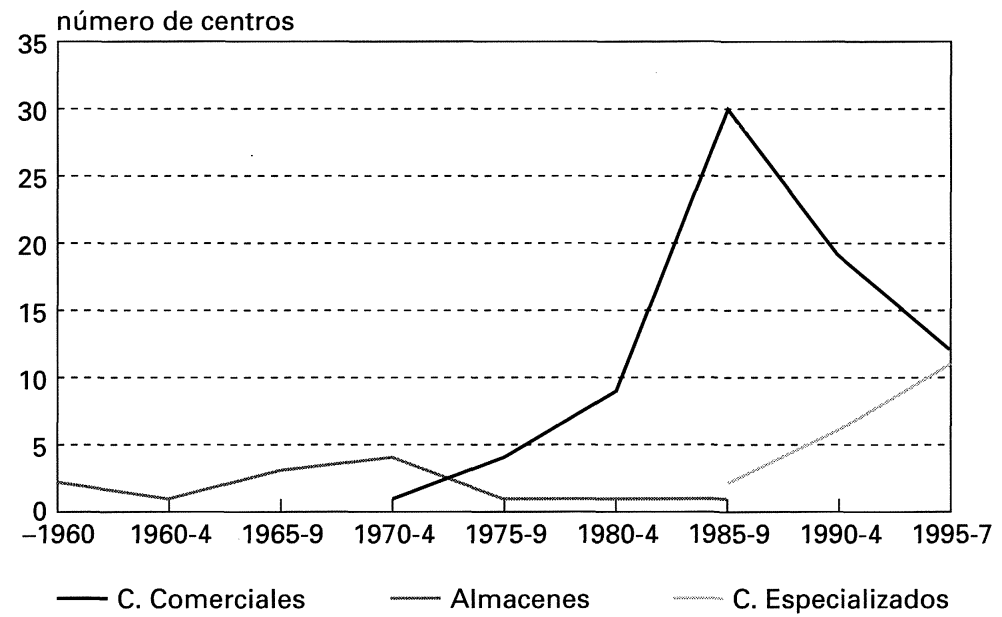

FIG. 1.-Evolución de las Grandes Superficies en el espacio metropolitano madrileño.

Los centros comerciales e hipermercados son más recientes. Los primeros centros comerciales se remontan a la primera mitad de los años setenta, y el primer hipermercado solo aparece en 1975. En ambos casos el

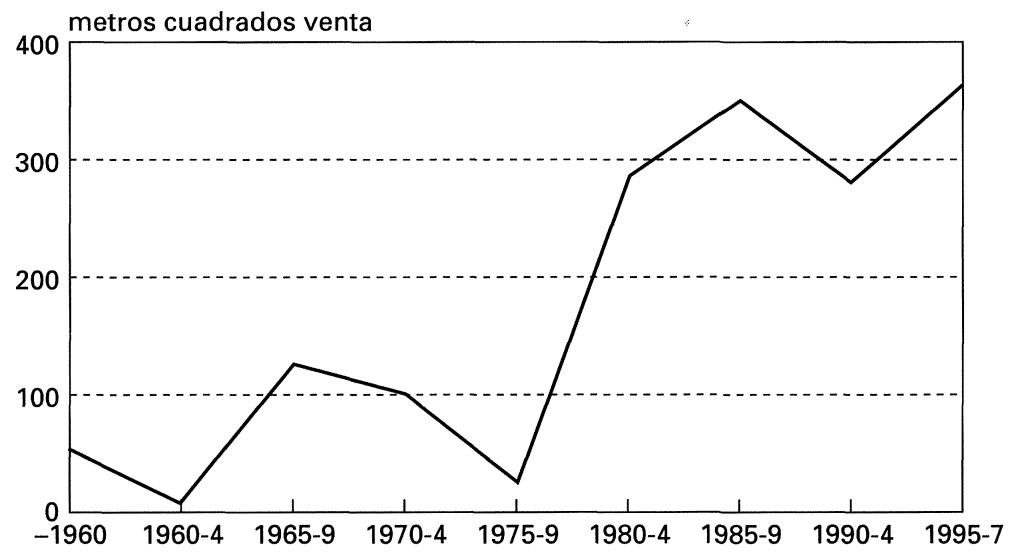

Fig. 2.-Evolución de la Superficie de venta en Grandes Superficies en el espacio metropolitano madrileño. 
crecimiento ha sido espectacular. Así desde los 5 establecimientos con un total de $33.889 \mathrm{~m}^{2}$ de la segunda mitad de los años setenta, se ha pasado a los 77 a fecha de julio de 1997, con una superficie de venta de 1.179 .355 $\mathrm{m}^{2}$, superando cada quinquenio las cifras del anterior. El mayor crecimiento se ha centrado en el período 1985-1997 ya que en esos doce años han abierto el $81 \%$ de los centros que engloban el $75 \%$ de toda la superficie de venta.

Por su parte las grandes superficies especializadas son más recientes, ya que se remontan a finales de los años ochenta, abriendo 17 de las 19 existentes en 1997 ya en los años noventa, con un período de mayor implantación posterior a 1994 coincidiendo con la salida de la última crisis económica.

En conjunto se observa el fuerte despegue de las grandes superficies desde principios de los ochenta, con un período de máximo esplendor en la segunda mitad de esa década coincidiendo con los años de recuperación económica, momento en el que se abren el mayor número de centros y el $22,5 \%$ de la superficie de venta al público. Los años de la crisis económica de los noventa suponen una pequeña ralentización en el proceso de implantación de las grandes superficies, para desde 1995 volver a una clara expansión como demuestra el hecho de que en tan solo dos años y medio se hayan abierto 23 centros y la mayor superficie de venta de su historia, el 23,5\%.

El análisis espacial (figura 3 y cuadro IV) muestra como las grandes superficies apenas si están presentes fuera del espacio metropolitano, solo 5 centros, y tienen mayor presencia en la corona metropolitana que en la Capital. Cerca del $70 \%$ de los centros y del $60 \%$ de la superficie de venta se localizan en los núcleos metropolitanos. Esta situación es resultado, ante todo, de la ubicación excéntrica de los grandes centros comerciales que engloban hipermercados, y de estos últimos cuando aparecen aislados.

Descendiendo en la escala, en la Capital hay un desequilibrio en número de centros y superficie a favor de los distritos de la Almendra Central, que sería mayor sin la presencia del centro de La Vaguada en el distrito de Fuencarral. En los distritos centrales se puede hablar incluso de una clara concentración, destacando sobre todo los de Centro y Salamanca, seguidos por los de Tetuán y Chamberí. En definitiva las zonas del comercio tradicional en el casco antiguo y ensanche, donde se han localizado la mayoría de los grandes almacenes y centros comerciales.

$$
-136-
$$




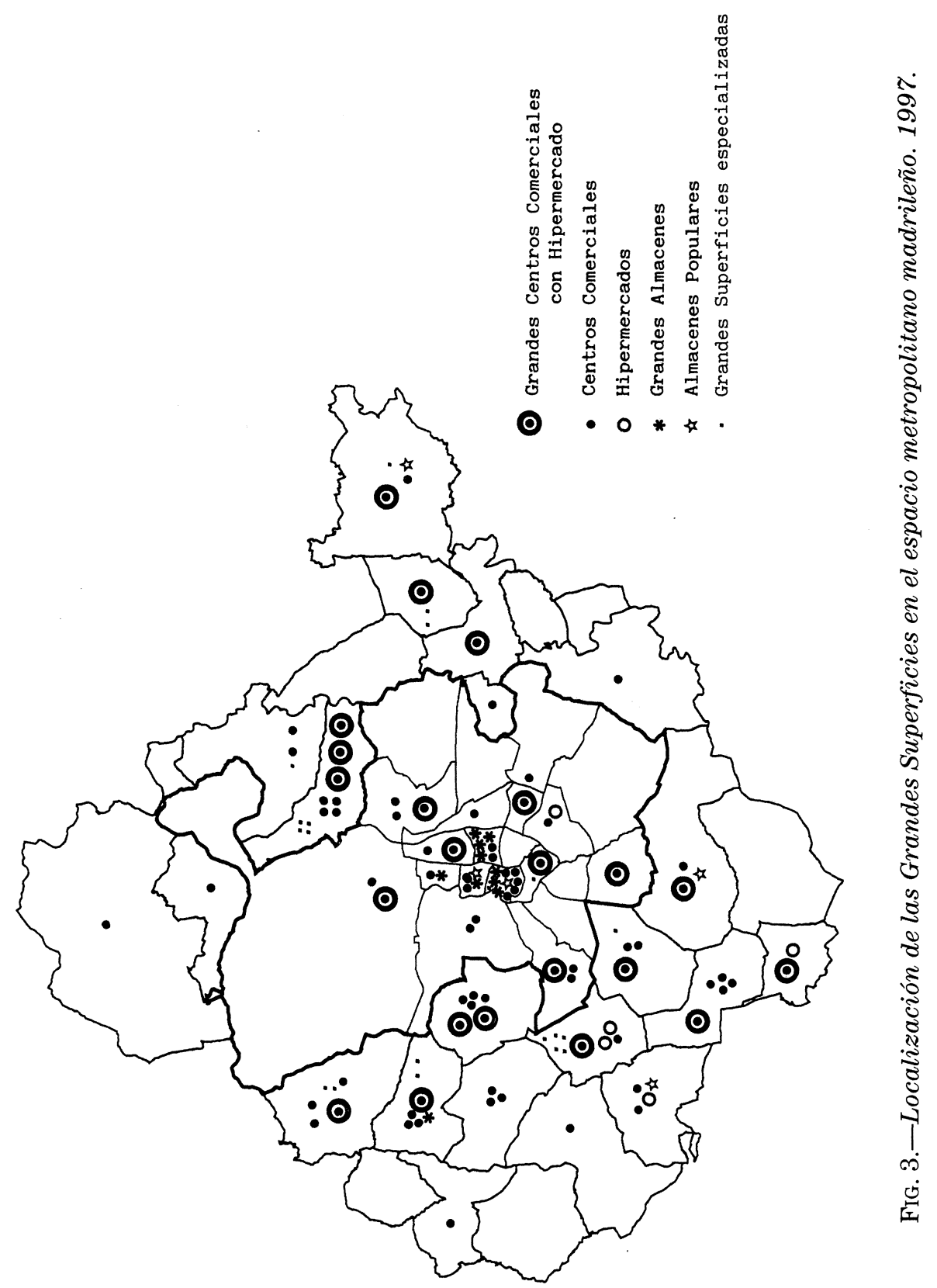

$-137-$ 
En la corona metropolitana destacan por su mayor dotación los sectores sur y oeste, en relación con la mayor concentración de población en el primero, y con el mayor nivel de renta de la población en el segundo. Los sectores norte y este tienen menos centros aunque similar superficie de venta que el sector oeste por el mayor tamaño de sus centros. En ambos la mayor parte de la superficie se concentra en dos municipios: Torrejón de Ardoz en el este con más de $100.000 \mathrm{~m}^{2}$ en un solo centro (Parque Corredor) y Alcobendas en el norte que con siete es el núcleo metropolitano más dotado.

Por último atendiendo a la tipología el $47 \%$ de toda la superficie de venta metropolitana se concentra en los grandes centros comerciales que integran un hipermercado (cuadro IV). Junto a los pocos hipermercados aislados, tienen una localización claramente excéntrica. En efecto 18 de los 28 centros existentes se localizan en núcleos metropolitanos, a los que se pueden sumar otros 8 situados en la periferia de la Capital. Esta ubicación se explica por la necesidad de contar con suelo abundante y barato. Por otro lado como necesitan para su rentabilidad umbrales de población elevados, su presencia en las áreas pericentrales y suburbanas de fuerte crecimiento demográfico y mal dotadas comercialmente se hace indispensable. En ellas hay una clara localización sobre los grandes ejes de circulación: las seis carreteras nacionales radiales y las dos vías de circunvalación (M-30 y M-40), confirmando su dependencia más que con la centralidad, con la accesibilidad, medida en facilidad de desplazamiento y aparcamiento. Constituyen el principal tipo de gran superficie en todas las áreas geográficas consideradas con solo dos excepciones: el sector oeste metropolitano donde dominan los centros comerciales sin hipermercado, de menor tamaño y más calidad y precios de los artículos para una población de mayor nivel de renta; y la Almendra Central de la Capital, donde están casi ausentes por la escasez de suelo vacante y su alto precio.

Los almacenes en sus dos tipos suponen el 15\% de los centros y el 18\% de la superficie. Históricamente son los más antiguos y siempre han buscado en su localización la máxima centralidad. Así el 95\% se ubican en los distritos centrales de Madrid, coincidiendo con las tradicionales zonas comerciales de la Capital. En la periferia y en los núcleos suburbanos su presencia se reduce a unos pocos almacenes populares.

Los centros comerciales sin hipermercado constituyen el segundo tipo de gran superficie en importancia, no por el número de centros (51) 


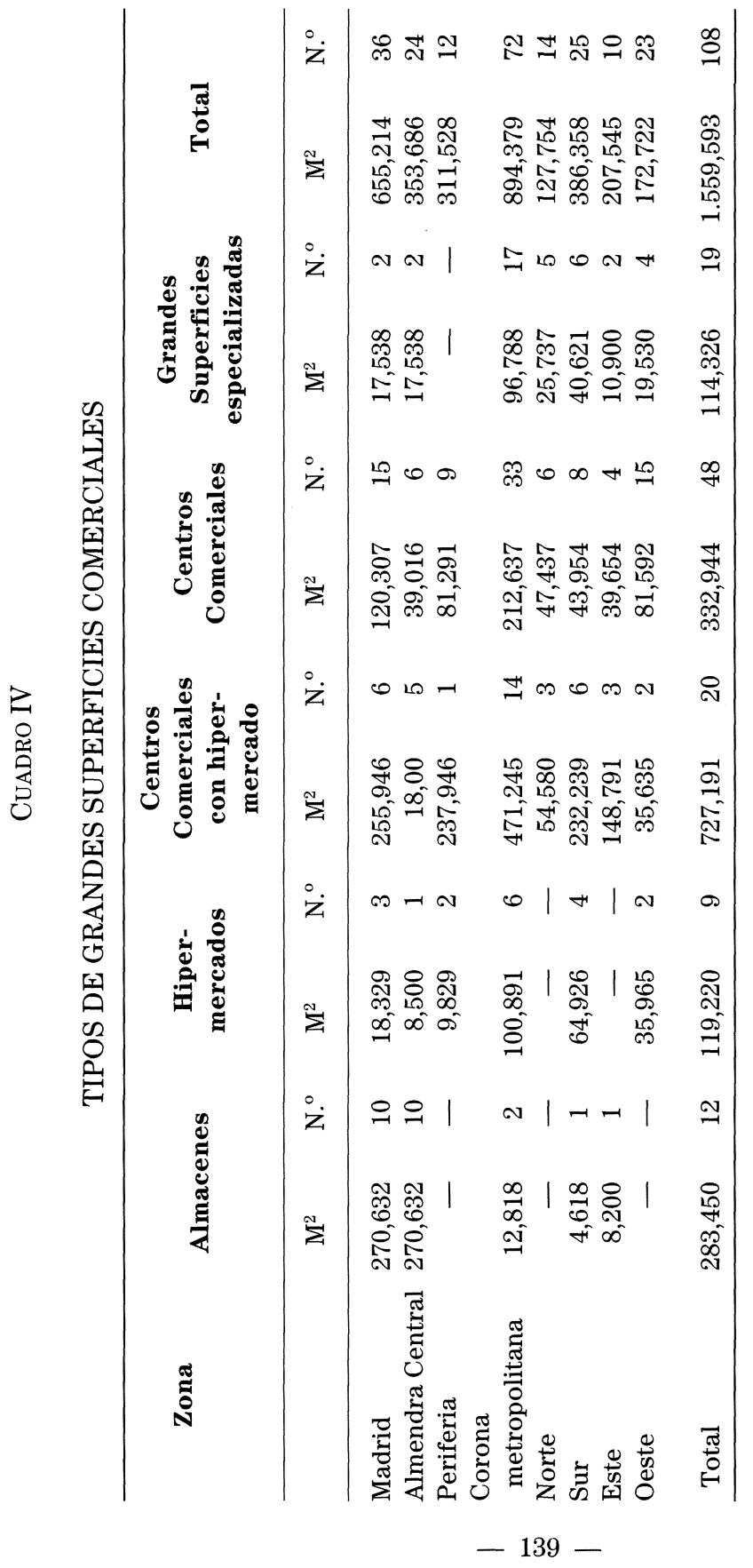


que la convierten en la más numerosa, sino por la superficie de venta que supone el $25 \%$ de la total. Los primeros centros aparecieron en la primera mitad de los años setenta bajo dos formas: como agrupación de establecimientos dedicados solo al comercio ocasional, ligados a operaciones de renovación urbana en las áreas de expansión del eje comercial tradicional; o como auténticas galerías comerciales, con un gran peso del comercio diario, en la periferia de la ciudad. Desde los años ochenta su crecimiento ha sido espectacular, extendiéndose a todo el conjunto metropolitano con una clara diversificación de tipologías. Así en algunos casos, sobre todo en la periferia, la tipología es la propia de las galería comerciales con un gran peso del comercio diario. En otros, localizados sobre todo en el área comercial tradicional del ensanche norte madrileño, prima la especialización en comercio ocasional de calidad, a la que se suma uno o varios locales de restauración. Hay casos también en los que estos locales se completan con un supermercado; y por último, tanto en la periferia madrileña como en los núcleos metropolitanos, centros planteados como lugar de compra con supermercado y lugar de consumo de ocio al tener una mayor oferta de cafeterías, restaurantes, cines, discotecas, galerías de exposiciones, etc.

Aunque estos centros comerciales se han extendido por toda la geografía metropolitana hay dos zonas que destacan por el número de centros y su superficie: la Almendra Central madrileña, con una fuerte especialización en comercio ocasional de calidad; y el sector oeste metropolitano, el de mayor crecimiento demográfico en los últimos diez años y más elevado nivel de renta de sus habitantes.

Los grandes centros especializados tienen una localización excéntrica. Solo 2 de los 19 centros se localizan en la Capital, en el mismo centro de la ciudad en un caso (FNAC) fácil de explicar por el tipo de artículos de venta que exige esa máxima accesibilidad. El resto se localiza en la corona metropolitana, coincidiendo con hipermercados aislados o centros comerciales con hipermercado, integrando en muchos casos con ellos y otros centros de ocio y esparcimiento, auténticos parques comerciales de tamaño diverso. En conjunto estas grandes superficies especializadas suponen ya el 17,5\% de todos los centros y el $7,5 \%$ de la superficie de venta, suponiendo una creciente y fuerte competencia para una forma comercial más tradicional como los grandes almacenes y los hipermercados. De hecho la respuesta de las cadenas distribuidoras ya instaladas se ha orientado bien a la 
apertura de centros especializados propios, bien a la redistribución de los centros ya existentes para conseguir un mayor grado de especialización de los mismos. Dentro de estas grandes superficies especializadas podemos destacar los parques de fabricantes de muy reciente implantación en el espacio madrileño. Un parque de fabricantes es una concentración de diferentes tiendas de fábrica que ofrecen marcas prestigiosas a un precio sensiblemente reducido ya que el surtido corresponde a excedentes de stock, restos de temporada o retornos no vendidos. Por el momento Factory-Las Rozas es el único parque de fabricantes instalado, pero en los próximos años se esperan nuevas aperturas.

Las grandes superficies comerciales traen consigo una nueva organización empresarial, en la que junto al predominio de la promoción profesionalizada hay dos hechos significativos: la presencia de grandes grupos de distribución que dominan el sector y la fuerte presencia del capital extranjero. El primer hecho resulta evidente si se tiene en cuenta que la mitad de odas las grandes superficies y de la superficie construida está en manos de tan solo cuatro cadenas de distribución (Promodes, Carrefour, Auchan y El Corte Inglés). El segundo hecho también es evidente. Salvo El Corte Inglés y Eroski el resto de empresas son de capital extranjero, fundamentalmente francés. Esta dependencia del exterior es

CuAdro V

RELACIÓN SUPERFICIE COMERCIAL/HABITANTE

\begin{tabular}{lcc}
\hline \multicolumn{1}{c}{ Zona } & $\begin{array}{c}\text { Superficie del } \\
\text { establecimiento } \\
\text { por habitante } \\
\left(\mathbf{m}^{\mathbf{2} / \mathbf{h a b} .)}\right.\end{array}$ & $\begin{array}{c}\mathbf{N}^{\mathbf{o}} \text { establecimiento } \\
\text { por habitante }\end{array}$ \\
\hline Madrid & 0,178 & \\
Almendra central & 0,323 & 1,36 \\
Periferia & 0,107 & 2,62 \\
Corona metropolitana & 0,418 & 0,84 \\
Norte & 0,686 & 3,35 \\
Sur & 0,296 & 5,80 \\
Este & 0,432 & 2,04 \\
Oeste & 0,782 & 1,86 \\
\hline
\end{tabular}


prácticamente total en el caso de los grandes centros especializados donde se observa una mayor diversificación de nacionalidades foráneas en la composición del capital.

Por último desde el punto de vista dotacional (cuadro V) se observa la mejor situación de la Corona Metropolitana que la de la Capital. Si descendemos en la escala del análisis, en la Capital la Almendra Central supera con claridad a la periferia tanto en número de centros por habitante como en superficie de venta por habitante, destacando a nivel distrito la mejor situación de Centro y Salamanca, junto a Fuencarral por la presencia del gran centro de La Vaguada. En la corona metropolitana la zona oeste es con mucho la mejor dotada, seguida por el sector norte, el este y el sur por este orden.

\section{BIBLIOGRAFÍA}

Ayuntamiento de MAdRID (1982): Recuperar Madrid, Oficina Municipal del Plan del Ayuntamiento de Madrid.

- (1985): Plan general de Ordenación Urbana 1985. Memoria General, Oficina Municipal del Plan del Ayuntamiento de Madrid.

- (1991): Revisión del Plan general de Ordenación Urbana de Madrid. Fase de Avan$c e$, Oficina Municipal del Plan del Ayuntamiento de Madrid.

- (1993): Revisión del Plan general de Ordenación Urbana de Madrid. Avance 1993. Memoria, Oficina Municipal del Plan del Ayuntamiento de Madrid.

CARRERAS I Verdaguer, C. (1995): «Los Nuevos Espacios del consumo en Barcelona», Revista de Geografía, n. ${ }^{\circ}$ 2. Departamentos de Geografía de la Universitat de Barcelona, pp. 69-77.

CASARES RIPOL, J. y MARTín CERDEÑo, V. ( 1998): «Tendencias y aspectos innovadores de la distribución comercial en Madrid». Situación, Serie Estudios Regionales: Madrid. Banco Bilbao-Vizcaya.

CONSEJERÍA DE ECONOMÍA DE LA CAM (1991): Guía de Grandes Superficies Comerciales de la CAM (actualización 1996).

(1991): Influencia de las Grandes Superficies Comerciales en la CAM.

lora-Tamayo, G.; Ríos Clemente, A.; Bodega Fernández, I.; Palacios Estremera, T.; Checa SÁNCHEZ, A. (1992): «Nuevas formas comerciales de gran superficie en la Comunidad de Madrid». Espacio, Tiempo y Forma, Serie VI, Geografía, tomo V, pp. 107-134.

SANABRIA BRASSART, C. (1986): «Las grandes superficies comerciales de Madrid», Ciudad y Territorio, n. ${ }^{\circ} 70 ;$ pp. $45-49$, Madrid.

TERÁN, F. (1978): «El planeamiento ante las nuevas formas comerciales», Ciudad y Territorio, n. ${ }^{\circ}$ 1/78; pp. $75-85$, Madrid.

RESUMEN: Dentro del proceso de transformación que se está produciendo en el comercio minorista el elemento más significativo es la aparición de nuevas formas comerciales que están modificando el mapa de la distribución en el espacio metropolitano madrileño.

En este artículo se analiza el proceso de crecimiento y las pautas de localización de las grandes superficies en sus diversos tipos (centros comerciales, hipermercados, grandes su-

$$
-142-
$$


perficies especializadas...), tras hacer un repaso al tratamiento dado por el Planeamiento al equipamiento comercial desde los años sesenta en el ámbito madrileño.

PALABRAS Claves: Actividad Comercial, Planeamiento, grandes superficies comerciales, espacio metropolitano madrileño.

ABSTRACT: A series of approaches to the new commerce are suddenly appearing inside the transformation of the market. This phenomenum is modifyng the map of the distribution of the commerce. The article reseaches the process of development and location patterns of the large shopps (shopping centers, chain stores, shopping malls...). It also copes with the trade equipment in the planning from the 60's in Madrid.

KEY wORDS: New commerce, commercial, activity, trading, planning, large shopps, large supermarket, Madrid and its surroundings. 